\title{
Communication
}

\section{ZnO ALD-Coated Microsphere-Based Sensors for Temperature Measurements}

\author{
Paulina Listewnik $^{1, *}$, Mikhael Bechelany ${ }^{2}{ }^{\oplus}$, Jacek B. Jasinski ${ }^{3}\left(\mathbb{D}\right.$ and Małgorzata Szczerska ${ }^{1}$ \\ 1 Department of Metrology and Optoelectronics, Faculty of Electronics, Telecommunications and Informatics, \\ Gdańsk University of Technology, 11/12 Narutowicza Street, 80-233 Gdańsk, Poland; malszcze@pg.edu.pl \\ 2 Institut Européen des Membranes, IEM-UMR 5635, University of Montpellier, ENSCM, CNRS, \\ 34095 Montpellier, France; mikhael.bechelany@umontpellier.fr \\ 3 Conn Center for Renewable Energy Research, University of Louisville, Louisville, KY 40292, USA; \\ jacek.jasinski@louisville.edu \\ * Correspondence: pauliste@student.pg.edu.pl
}

Received: 7 July 2020; Accepted: 18 August 2020; Published: 20 August 2020

\begin{abstract}
In this paper, the application of a microsphere-based fiber-optic sensor with a $200 \mathrm{~nm}$ zinc oxide $(\mathrm{ZnO})$ coating, deposited by the Atomic Layer Deposition (ALD) method, for temperature measurements between 100 and $300{ }^{\circ} \mathrm{C}$, is presented. The main advantage of integrating a fiber-optic microsphere with a sensing device is the possibility of monitoring the integrity of the sensor head in real-time, which allows for higher accuracy during measurements. The study has demonstrated that ZnO ALD-coated microsphere-based sensors can be successfully used for temperature measurements. The sensitivity of the tested device was found to be $103.5 \mathrm{nW} /{ }^{\circ} \mathrm{C}$ when the sensor was coupled with a light source of $1300 \mathrm{~nm}$ central wavelength. The measured coefficient $\mathrm{R}^{2}$ of the sensor head was over 0.99 , indicating a good fit of the theoretical linear model to the measured experimental data.
\end{abstract}

Keywords: atomic layer deposition; fiber-optic; microsphere; temperature; $\mathrm{ZnO}$

\section{Introduction}

Temperature is one of the most important parameters, measured in many different fields, such as science, medicine or industry [1-5]. It is used to monitor quality of the products, procedures and energy consumption. Accurate temperature measurements are highly dependent on carefully chosen instruments, which should be selected based on conditions in which the device will be used, external influences and the parameters suitable for each task, especially temperature range, pollution, sensitivity and period of time, over which the measurements will be performed [6,7].

One of the fields, where the temperature is strictly controlled is the food industry. This is to ensure that the proper standards are preserved and to minimize the risks, such as bacteria growth and formation of toxins, while processing and storing the food [8,9]. Maintaining the right temperature helps to avoid food poisoning or its spoiling [10,11]. Another area, where those measurements are also highly utilized are electrochemical batteries and energy storage cells, where temperature control is used to monitor device performance and stability during charging cycles, therefore preserving its properties for as long as possible and estimating its lifetime [12,13]. Monitoring temperature is also useful during plastic or metal production to ensure the quality of the products and workplace security [14-16].

There is an abundance of instruments for temperature measurements, from contact sensors, such as thermocouples and thermistors to contactless devices, i.e., infrared thermal detectors [17-19]. Among them, all fiber-optic sensors stand out and, as a consequence, their development has been steadily progressing throughout the years thanks to the ease of use of these devices, their high durability, low fabrication cost, and chemical inertness [20-22]. Over the last decade, researchers gained new measurement 
techniques using fiber-optic sensors, such as: hybrid fiber-optic sensing, GOD-complex-based (glucose oxidase complex) sensors, multi-parameter sensors, deformable micro-mirror sensors or core-offset splicing [23-28]. The requirement for the long-term monitoring of temperature in severe, remote conditions caused fiber-optic sensors application in many fields, including industry, e.g., building applications, oil leakage railway infrastructure [29-33], but also they are used in biochemistry [34]. Moreover, fiber-optic sensors can be adapted to best suit the needs of specific applications, by modifying geometrical parameters or by adding additional passive components, such as coatings [35-37].

In traditional fiber-optic sensors, many desired properties have been hampered by low sensitivity, limited measurement range and the lack of protection against mechanical damage. In order to address these shortcomings, the sensors with various coatings (metal, metal oxides, diamond, etc.), deposited on the surface of the sensor head by different methods (atomic layer deposition, magnetron sputtering, electron beam evaporation e-beam) [38-40], have started to be developed in recent years.

Geometrical modifications have also been introduced to increase resolution, employ phenomena such as resonance or Whispering Mode Gallery, and control the optical path of the light within the utilized medium [41]. The most used optical-fiber structures include tapers and microspheres [42,43].

One of the most challenging aspects in remote sensing, especially under volatile conditions, is determining whether the integrity of the sensor head remains preserved. Ensuring that the sensor head keeps its integrity, it helps to eliminate inaccuracies from the obtained data and prevent major disruptions of the measurement process. Incorporating a microsphere to the fiber-optic sensor allows one to monitor the state of the sensor head during real-time measurements.

This work presents the advantages of combining a fiber-optic microsphere and $\mathrm{ZnO}$ (zinc oxide) ALD (Atomic Layer Deposition) $200 \mathrm{~nm}$ coating into one sensor, designed for temperature measurements at the central wavelength of $1300 \mathrm{~nm}$.

\section{Materials and Methods}

\subsection{Microsphere Development}

The fiber-optic microsphere was manufactured at the end of a standard single-mode optical fiber (SMF-28, Thorlabs Inc., Newton, NJ, USA) by using an electric arc from the splicer (FSU975, Ericsson, Sweden), which provided sufficient energy to affect the original structure of the fiber and allowed for the microsphere to be formed by a three-step pull. During the fabrication process, the splicing parameters were carefully controlled, ensuring the high reproducibility of the microsphere structure. The diameter of the microsphere used for this study was $245 \mu \mathrm{m}$.

The microsphere was coated with a 200-nm-thick ZnO layer using Atomic Layer Deposition (ALD), as described elsewhere [38,44].

The described device worked as an interferometric fiber-optic sensor with an intrinsic fixed cavity. The principle of the operation of the sensor is shown in Figure 1.

During operation, part of the optical signal propagating through the fiber is reflected at the boundary between the core and the cladding of the microsphere, whereas the rest passes through and reflects off the microsphere surface. Cross-section of the sensor head presented in Figure $1 \mathrm{~b}$ provides visualization how the signal propagates through the sensor.

These two beams interfere with each other. While the reflection on the boundary between the core and the cladding is constant, the reflection from the microsphere surface depends on the optical properties of the deposited $\mathrm{ZnO}$ coating. By adjusting the thermal radiation around the device, the $\mathrm{ZnO}$ coating is influenced, which affects the intensity of the output signal.

The sensor head has been subjected to Scanning Electron Microscopy (SEM) imaging to provide the characterization of the $\mathrm{ZnO}$ coating after its deposition on the surface of the microsphere. The image presented in Figure 2 is of $5000 \times$ magnification and it shows the uniformity of the ALD ZnO coating. 
(a)

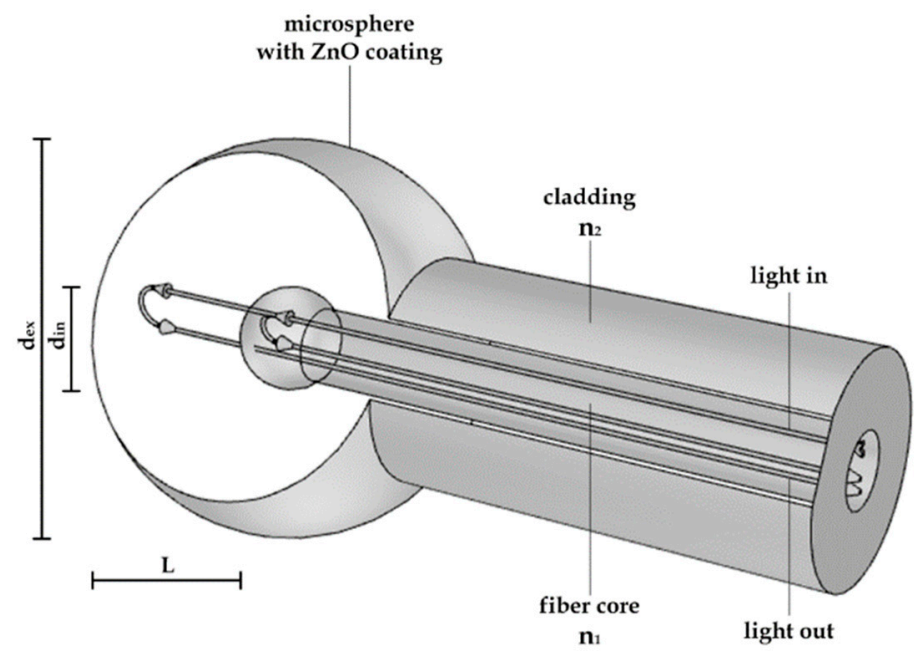

ALD ZnO coated

(b)

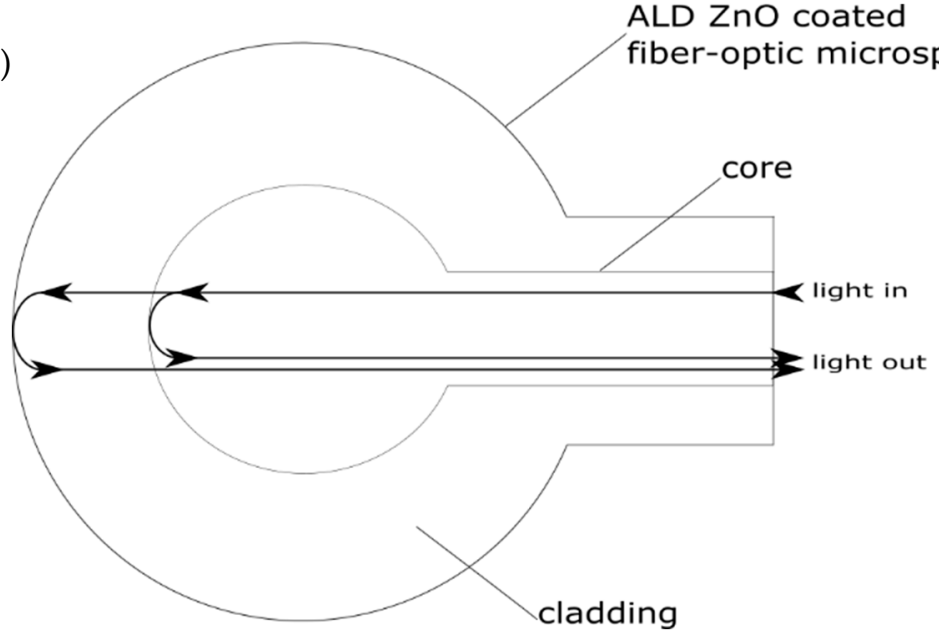

Figure 1. Principle of operation of the microsphere-based sensor with ZnO Atomic Layer Deposition (ALD) coating for temperature measurement: (a) schematic representation of a sensor, (b) cross-section of the sensor head.

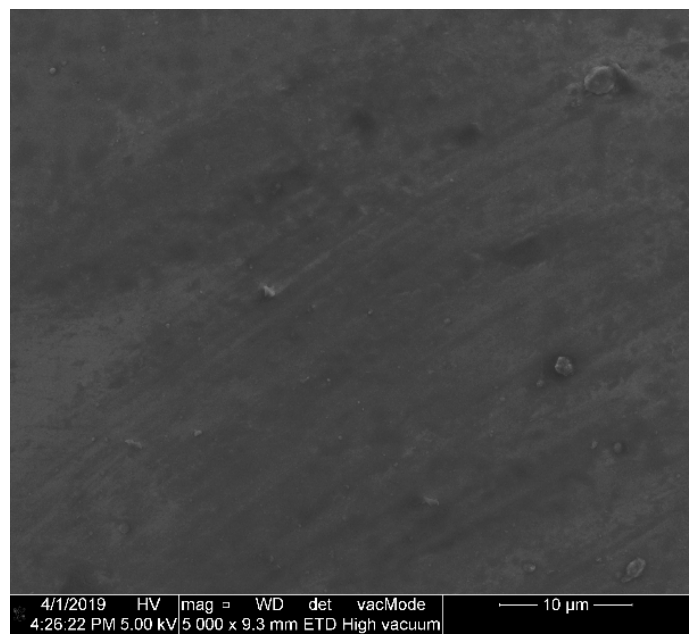

Figure 2. Scanning Electron Microscopy (SEM) image of the ALD ZnO coating deposited on the surface of the microsphere with $5000 \times$ magnification. 


\subsection{Experimental Setup}

To validate the sensing capabilities of the device, experimental measurements were performed. Test measurements were performed in order to obtain a spectral response of the signal during temperature changes. The temperature was measured using a low-coherence light source, temperature calibrator and an optical signal analyzer in a configuration presented in Figure 3.

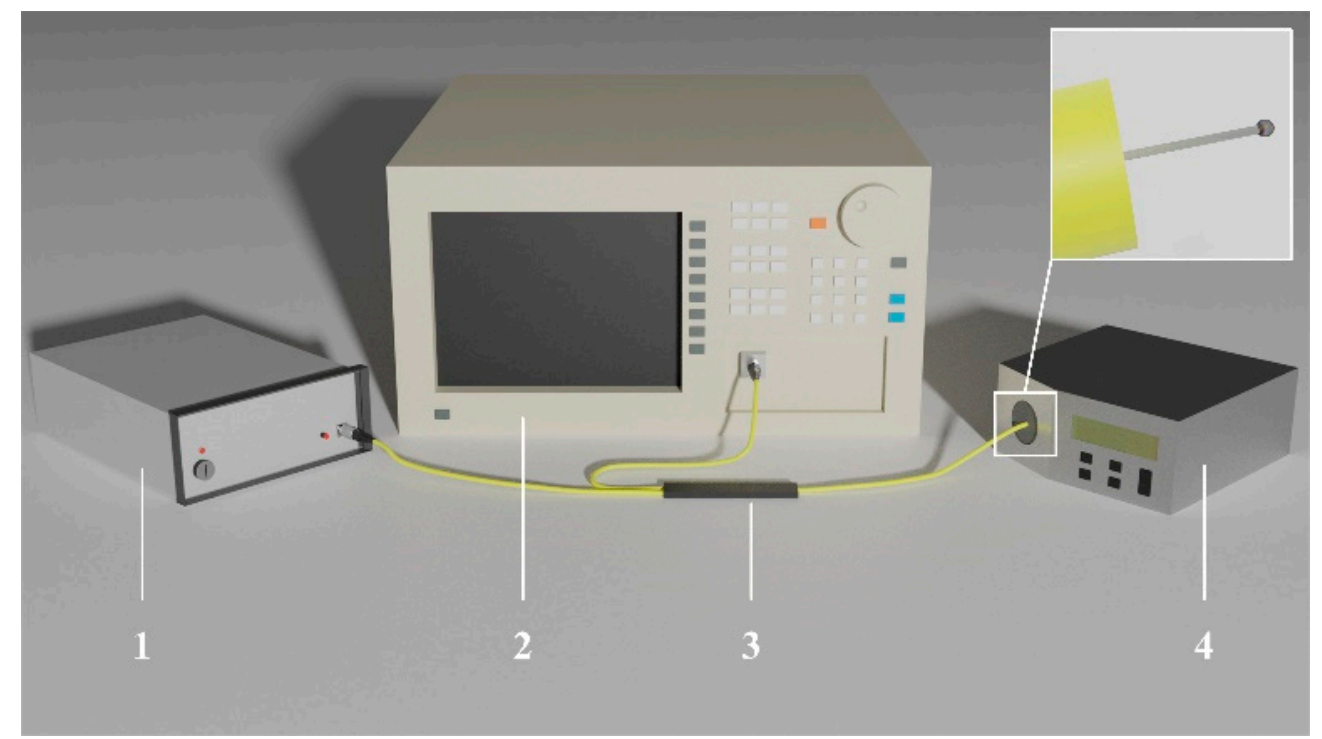

Figure 3. Schematic of the experimental setup used for temperature measurement, where: 1-superluminescent diode, 2-Optical Signal Analyzer, 3-optical coupler, 4-temperature calibrator.

During measurements, an optical signal, that was generated and provided by the low-coherent light source-superluminescent diode with a center wavelength of $1310 \mathrm{~nm}$ (SLD-1310-18-W, FiberLabs Inc., Fujimino, Japan), propagated through a typical 2:1 50/50\% optical coupler (G657A, CELLCO, Kobylanka, Poland) to the microsphere-based fiber-optic sensor, placed in the temperature calibrator (ETC-400A, Ametek, Berwyn, PA, USA).

The reflected signal intensity was measured in a temperature range from 100 to $300{ }^{\circ} \mathrm{C}$ with a $10{ }^{\circ} \mathrm{C}$ step. The temperature was adjusted every $5 \mathrm{~min}$ in order to allow the sensor to adapt to the change. After the signal was reflected by the microsphere, it was received and analyzed by the Optical Signal Analyzer (OSA, Ando AQ6319, Yokohama, Japan).

\section{Results and Discussion}

The results presented in this section were obtained according to the procedures described in Section 2.

Several series of measurements were carried out in order to test the device temperature sensing abilities. During measurements, the sensor head was placed inside the temperature calibrator, while the range was increased with $10^{\circ} \mathrm{C}$ steps, between 100 and $300{ }^{\circ} \mathrm{C}$.

Figure 4 shows an example of the measured response of the microsphere-based fiber-optic sensor at a wavelength of $1300 \mathrm{~nm}$. As shown, the intensity of the reflected signal increased with the increase in the temperature. Not all of the measured responses were plotted to maintain clarity of the graph. A slight shift in wavelength $( \pm 2 \mathrm{~nm})$ is a result of an optical coupler loss. 


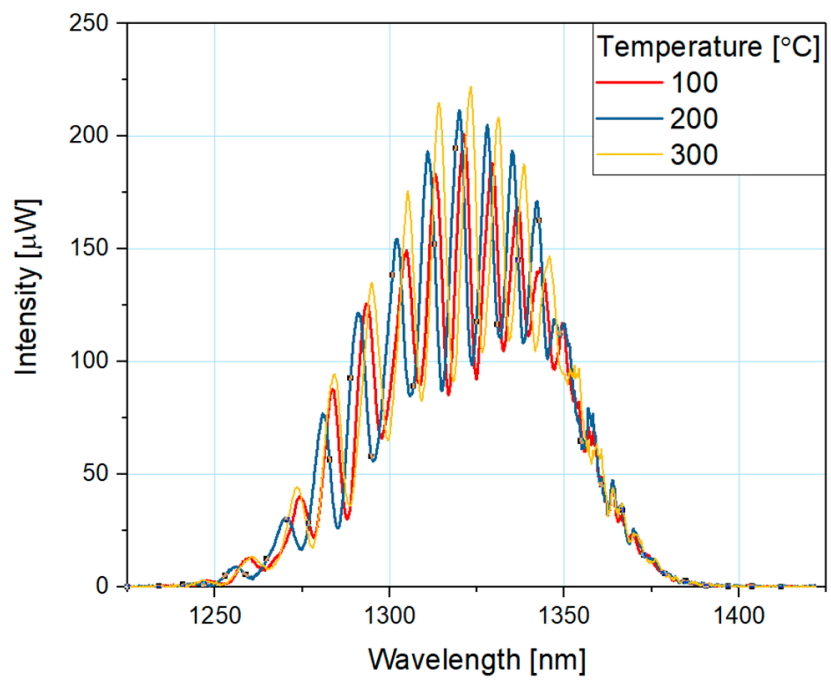

Figure 4. Measured response of the reflected signal intensity for the microsphere-based sensor with $200 \mathrm{~nm} \mathrm{ZnO}$ ALD coating at 100,200 and $300^{\circ} \mathrm{C}$.

The temperature dependence of the reflected signal peak intensity measured in the entire temperature range is presented in Figure 5. Additionally, Figure 5 shows a theoretical linear fit indicating the accuracy of the device. As shown, the intensity of the reflected signal increased linearly with the temperature. The obtained coefficient $R^{2}$, which represents the quality of the fit, is 0.995 , i.e., close to 1 , suggesting good agreement of the experimental data and theoretical linear fit.

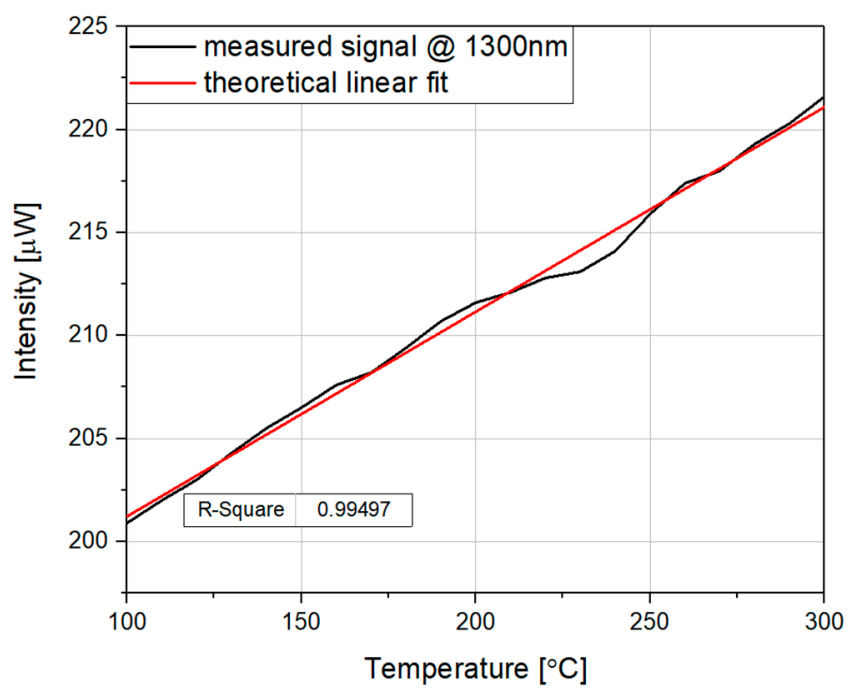

Figure 5. Dependence of the reflected signal peak intensity vs. temperature for a microsphere-based sensor with $200 \mathrm{~nm} \mathrm{ZnO} \mathrm{ALD} \mathrm{coating,} \mathrm{measured} \mathrm{at} \mathrm{a} \mathrm{wavelength} \mathrm{of} 1300 \mathrm{~nm}$. A theoretical linear fit is also included.

The sensitivity of the sensor was calculated according to Formula (1):

$$
S=\frac{\Delta I}{\Delta T}
$$

where: S-sensitivity, $\Delta I$-intensity, $\Delta T$-temperature.

The sensitivity of the sensor calculated from the data in Figure 5 equals $103.5 \mathrm{nW} /{ }^{\circ} \mathrm{C}$.

The presented results indicate that the microsphere-based sensor with $200 \mathrm{~nm}$ ZnO ALD coating is a promising device for temperature measurements. The described device maintains stable conditions 
to perform such measurements. In addition, its design provides an opportunity for constant, real-time monitoring of the integrity of the sensor head structure.

\section{Conclusions}

This paper introduces a $\mathrm{ZnO}$ ALD coated microsphere-based sensor for temperature measurements. The presented $\mathrm{ZnO}$ ALD coated microsphere-based sensor is demonstrated to be a precise device ideal for long-term monitoring temperature, which is crucial for industrial applications, such as manufacturing, processing, storing and controlling products in various sectors. Investigated sensor is a reliable device during harsh conditions and remote or hard-to-get places, where the cost of measurement system is balanced by safety considerations or service and operation costs. The presented sensor can, for example, be utilized for the investigation of processes occurring inside of electrochemical battery cells during their charging-discharging cycles. The sensor is fabricated at the end-face of an optical fiber and the coating of $200 \mathrm{~nm}$ in thickness is deposited on its surface by the ALD method. By using a microsphere sensor head, not only can the measured parameters be controlled, but also the structural integrity of the sensor. To optimize the metrological parameters of the device, such as sensitivity or resolution, the thickness of the coating can be modified as needed [44].

Author Contributions: Conceptualization, P.L. and M.S.; methodology, P.L. and M.S.; validation, P.L. and M.S.; formal analysis, P.L. and M.S.; investigation, P.L.; writing—original draft preparation, P.L and M.S.; writing-review and editing, M.B. and J.B.J.; visualization, P.L.; supervision, M.S.; funding acquisition, M.S. and M.B. All authors have read and agreed to the published version of the manuscript.

Funding: The authors acknowledge the financial support of the Polish National Agency for Academic Exchange-NAWA under bilateral exchange of scientists between France and Poland PHC Polonium (PPN/BFR/2019/1/00005). The authors P.L. and M.S. acknowledge the financial support of the DS Programs of the Faculty of Electronics, Telecommunications and Informatics of the Gdańsk University of Technology.

Acknowledgments: P.L. would like to thank Katarzyna Gajdecka for valuable help in the visualization of the sensor head.

Conflicts of Interest: The authors declare no conflict of interest.

\section{References}

1. Sergeyev, D.; Solovjov, A.; Shunkeyev, K.; Zhanturina, N. Temperature dependences of the excess current and pseudogap in high-temperature superconductor Bi2Sr2CaCu2O9. In Proceedings of the 2017 International Siberian Conference on Control and Communications (SIBCON), Astana, Kazakhstan, 29-30 June 2017; pp. 1-6.

2. Teunissen, L.P.J.; Klewer, J.; de Haan, A.; de Koning, J.J.; Daanen, H.A.M. Non-invasive continuous core temperature measurement by zero heat flux. Physiol. Meas. 2011, 32, 559-570. [CrossRef] [PubMed]

3. D'Acquisto, L.; Scardulla, F.; Pasta, S. Steam sterilization processes affect the stability of clinical thermometers: Thermistor and prototypal FBG probe comparison. Opt. Fiber Technol. 2020, 55, 102156. [CrossRef]

4. Kocjan, B.; Krawczyk, K.; Snopek, L.; Jasinski, R.; Dudek, E. Temperature chamber with precise temperature stability. In Proceedings of the 2018 Conference on Precision Electromagnetic Measurements (CPEM 2018), Paris, France, 8-13 July 2018; pp. 1-2.

5. Jia, R.; Xiong, Q.; Liang, S.; Shi, W.; Wang, L. The study of temperature distribution reconstruction based on the singular value decomposition and the griddata interpolation algorithm in industry microwave heating. In Proceedings of the 27th Chinese Control and Decision Conference (2015 CCDC), Qingdao, China, 16-18 July 2015; pp. 4015-4020.

6. Chen, P.-K.; Chen, C.-H.; Lin, S.-C.; Kuan, Y.-T.; Lin, H.-L.; Chen, J.-W. Study of the Water Temperature and Quality Change with Hot and Cold Springs. In Proceedings of the 2017 International Conference on Information, Communication and Engineering (ICICE), Xiamen, China, 17-20 November 2017; pp. $193-196$.

7. Wang, W.; Ma, Z.; Wang, X.; Li, C.; Ma, J.; Long, K.; Hao, Z.; Liu, S.; Wu, Y. Distribution of moisture in oil immersed pressboard under transient temperature condition. In Proceedings of the 2012 IEEE International Conference on Condition Monitoring and Diagnosis, Bali, Indonesia, 23-27 September 2012; pp. 897-900. 
8. Vadivambal, R.; Jayas, D.S. Applications of thermal imaging in agriculture and food industry-A review. Food Bioprocess Technol. 2011, 4, 186-199. [CrossRef]

9. Raghunathan, N.; Xiaofan, J.; Peroulis, D.; Ganguly, A. Wireless low-power temperature probes for food/pharmaceutical process monitoring. In Proceedings of the 2015 IEEE SENSORS, Busan, Korea, 1-4 November 2015; pp. 1-4.

10. Patel, H.; Sheth, S.; Farhad, S.M. Cloud based temperature and humidity alert system to prevent food poisoning. In Proceedings of the 2019 Cybersecurity and Cyberforensics Conference (CCC), Melbourne, Australia, 8-9 May 2019; pp. 1-5.

11. Bansal, B.; Chen, X.D. Effect of temperature and power frequency on milk fouling in an ohmic heater. Food Bioprod. Process. 2006, 84, 286-291. [CrossRef]

12. Mutyala, M.S.K.; Zhao, J.; Li, J.; Pan, H.; Yuan, C.; Li, X. In-situ temperature measurement in lithium ion battery by transferable flexible thin film thermocouples. J. Power Sources 2014, 260, 43-49. [CrossRef]

13. Novais, S.; Nascimento, M.; Grande, L.; Domingues, M.F.; Antunes, P.; Alberto, N.; Leitão, C.; Oliveira, R.; Koch, S.; Kim, G.T.; et al. Internal and external temperature monitoring of a Li-Ion battery with fiber bragg grating sensors. Sensors 2016, 16, 1394. [CrossRef]

14. Utada, S.; Rame, J.; Hamadi, S.; Delautre, J.; Villechaise, P.; Cormier, J. Kinetics of creep damage accumulation induced by a room-temperature plastic deformation introduced during processing of AM1 Ni-based single crystal superalloy. Mater. Sci. Eng. A 2020, 789, 139571. [CrossRef]

15. Jung, J.G.; Lee, K.; Lee, B.; Lee, H.S. Effect of rapid thermal annealing on bulk micro-defects and plastic deformation in silicon during high temperature processing. Mater. Sci. Semicond. Process. 2018, 85, 83-89. [CrossRef]

16. Dubois, A.; Dubar, M.; Dubar, L. Warm and hot upsetting sliding test: Tribology of metal processes at high temperature. Procedia Eng. 2014, 81, 1964-1969. [CrossRef]

17. Debey, D.; Bluhm, R.; Habets, N.; Kurz, H. Fabrication of planar thermocouples for real-time measurements of temperature profiles in polymer melts. Sens. Actuators A Phys. 1997, 58, 179-184. [CrossRef]

18. Souza, E.L.d.J.; Santos, T.L.M. Transient compensation for thermistor-based sensors in constant temperature configuration. Sens. Actuators A Phys. 2020, 305, 111920. [CrossRef]

19. Zhao, B.; Feng, F.; Tian, B.; Yu, Z.; Li, X. Micro thermal conductivity detector based on SOI substrate with low detection limit. Sens. Actuators B Chem. 2020, 308, 127682. [CrossRef]

20. Bhadra, S.; Tan, D.S.Y.; Thomson, D.J.; Freund, M.S.; Bridges, G.E. A wireless passive sensor for temperature compensated remote $\mathrm{pH}$ monitoring. IEEE Sens. J. 2013, 13, 2428-2436. [CrossRef]

21. Guo, Y.; Xiong, L.; Liu, H. Research on the durability of metal-packaged fiber bragg grating sensors. IEEE Photon. Technol. Lett. 2019, 31, 525-528. [CrossRef]

22. Wen, J.; Liu, W.; Huang, Y.; Liu, Y.; Luo, Y.; Peng, G.-D.; Pang, F.; Chen, Z.; Wang, T. Spun-related effects on optical properties of spun silica optical fibers. J. Lightwave Technol. 2015, 33, 2674-2678. [CrossRef]

23. Chen, K.; Zhou, X.; Yang, B.; Peng, W.; Yu, Q. A hybrid fiber-optic sensing system for down-hole pressure and distributed temperature measurements. Optics Laser Technol. 2015, 73, 82-87. [CrossRef]

24. Huang, J.; Zhang, P.; Li, M.; Zhang, P.; Ding, L. Complex of hydrogel with magnetic immobilized GOD for temperature controlling fiber optic glucose sensor. Biochem. Eng. J. 2016, 114, 262-267. [CrossRef]

25. Bremer, K.; Reinsch, T.; Leen, G.; Roth, B.; Lochmann, S.; Lewis, E. Pressure, temperature and refractive index determination of fluids using a single fibre optic point sensor. Sens. Actuators A Phys. 2017, 256, 84-88. [CrossRef]

26. Velázquez-González, J.S.; Monzón-Hernández, D.; Moreno-Hernández, D.; Martínez-Piñón, F.; Hernández-Romano, I. Simultaneous measurement of refractive index and temperature using a SPR-based fiber optic sensor. Sens. Actuators B Chem. 2017, 242, 912-920. [CrossRef]

27. Guermat, A.; Guessoum, A.; Demagh, N.-E.; Zaboub, M.; Bouhafs, Z. Fibre-optic temperature and pressure sensor based on a deformable concave micro-mirror. Sens. Actuators A Phys. 2018, 270, 205-213. [CrossRef]

28. Gao, S.; Ji, C.; Ning, Q.; Chen, W.; Li, J. High-sensitive Mach-Zehnder interferometric temperature fiber-optic sensor based on core-offset splicing technique. Opt. Fiber Technol. 2020, 56, 102202. [CrossRef]

29. Tregubov, A.V.; Svetukhin, V.V.; Novikov, S.G.; Berintsev, A.V.; Prikhodko, V.V. A novel fiber optic distributed temperature and strain sensor for building applications. Results Phys. 2016, 6, 131-132. [CrossRef]

30. Kesavan, K.; Ravisankar, K.; Parivallal, S.; Sreeshylam, P.; Sridhar, S. Experimental studies on fiber optic sensors embedded in concrete. Measurement 2010, 43, 157-163. [CrossRef] 
31. Mirzaei, A.; Bahrampour, A.R.; Taraz, M.; Bahrampour, A.; Bahrampour, M.J.; Ahmadi Foroushani, S.M. Transient response of buried oil pipelines fiber optic leak detector based on the distributed temperature measurement. Int. J. Heat Mass Transf. 2013, 65, 110-122. [CrossRef]

32. Fuhr, P.L.; Huston, D.R. Corrosion detection in reinforced concrete roadways and bridges via embedded fiber optic sensors. Smart Mater. Struct. 1998, 7, 217-228. [CrossRef]

33. Du, C.; Dutta, S.; Kurup, P.; Yu, T.; Wang, X. A review of railway infrastructure monitoring using fiber optic sensors. Sens. Actuators A Phys. 2020, 303, 111728. [CrossRef]

34. Huang, J.; Liu, Y.; Zhang, P.; Li, Y.; Ding, L. A temperature-triggered fiber optic biosensor based on hydrogel-magnetic immobilized enzyme complex for sequential determination of cholesterol and glucose. Biochem. Eng. J. 2017, 125, 123-128. [CrossRef]

35. Gomes, A.D.; Monteiro, C.S.; Silveira, B.; Frazão, O. A brief review of new fiber microsphere geometries. Fibers 2018, 6, 48. [CrossRef]

36. Renganathan, B.; Sastikumar, D.; Gobi, G.; Rajeswari Yogamalar, N.; Chandra Bose, A. Nanocrystalline ZnO coated fiber optic sensor for ammonia gas detection. Optics Laser Technol. 2011, 43, 1398-1404. [CrossRef]

37. Wang, Y.; Yang, M.; Zhang, G.; Dai, J.; Zhang, Y.; Zhuang, Z.; Hu, W. Fiber optic hydrogen sensor based on fabry-perot interferometer coated with Sol-Gel Pt/WO 3 coating. J. Lightwave Technol. 2015, 33, 2530-2534. [CrossRef]

38. Listewnik, P.; Hirsch, M.; Struk, P.; Weber, M.; Bechelany, M.; Jędrzejewska-Szczerska, M. Preparation and characterization of microsphere $\mathrm{ZnO}$ ALD coating dedicated for the fiber-optic refractive index sensor. Nanomaterials 2019, 9, 306. [CrossRef] [PubMed]

39. Niedziałkowski, P.; Białobrzeska, W.; Burnat, D.; Sezemsky, P.; Stranak, V.; Wulff, H.; Ossowski, T.; Bogdanowicz, R.; Koba, M.; Śmietana, M. Electrochemical performance of indium-tin-oxide-coated lossy-mode resonance optical fiber sensor. Sens. Actuators B Chem. 2019, 301, 127043. [CrossRef]

40. Wei, H.; Yunhui, D.; Lianqing, Z.; Mingli, D. Angular sensing system based on Y-type twin-core fiber and reflective varied-line spacing grating fabricated by electron beam lithography. Results Phys. 2020, 18, 103193. [CrossRef]

41. Ma, Q.; Rossmann, T.; Guo, Z. Whispering-gallery mode silica microsensors for cryogenic to room temperature measurement. Meas. Sci. Technol. 2010, 21, 025310. [CrossRef]

42. Vikas; Verma, R.K. Design considerations of a surface plasmon resonance (SPR) based tapered fiber optic bio-sensing probe with graphene-MoS2 over layers. Optik 2019, 180, 330-343. [CrossRef]

43. Cai, L.; Wang, J.; Pan, J.; Liu, Q.; Chen, Y. A tunable fiber-optic Fabry-Perot cavity formed between a silica microsphere and a target. Opt. Commun. 2020, 459, 124996. [CrossRef]

44. Hirsch, M.; Listewnik, P.; Struk, P.; Weber, M.; Bechelany, M.; Szczerska, M. ZnO coated fiber optic microsphere sensor for the enhanced refractive index sensing. Sens. Actuators A Phys. 2019, 298, 111594. [CrossRef] 